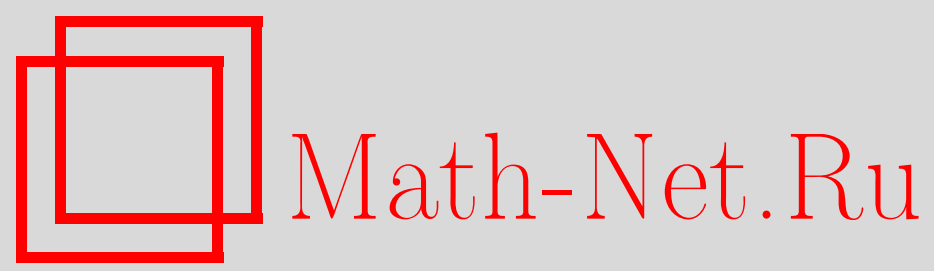

Г. И. Элькин, В. В. Говоритель, Метод построения моделей процессов информационно-аналитической деятельности субъектов жизненного цикла автоматизированных систем военного назначения, Вестник ТвГУ. Серия: Прикладная математика, 2019, выпуск 3, 53-63

DOI: https://doi.org/10.26456/vtpmk539

Использование Общероссийского математического портала Math-Net.Ru подразумевает, что вы прочитали и согласны с пользовательским соглашением

http://www.mathnet.ru/rus/agreement

Параметры загрузки:

IP : 18.234 .156 .22

26 апреля 2023 г., $18: 15: 38$ 


\section{УДК 623.618 \\ МЕТОД ПОСТРОЕНИЯ МОДЕЛЕЙ ПРОЦЕССОВ ИНФОРМАЦИОННО-АНАЛИТИЧЕСКОЙ ДЕЯТЕЛЬНОСТИ СУБЪЕКТОВ ЖИЗНЕННОГО ЦИКЛА АВТОМАТИЗИРОВАННЫХ СИСТЕМ ВОЕННОГО НАЗНАЧЕНИЯ}

Элькин Г.И.*, Говоритель В.В.**

*AO «Объединённая приборостроительная корпорация», г. Москва

** Военная академия воздушно-космической обороны имени Маршала Советского Союза Г.К. Жукова, г. Тверь

Поступила в редакцию 27.08.2019, после переработки 20.09.2019.

Рассмотренный в статье метод позволяет сократить количество итераций по информационному обследованию объектов автоматизации в части описания, классификации и построению моделей процессов информационно-аналитической деятельности субъектов жизненного цикла автоматизированных систем военного назначения с целью последующей автоматизации процессов документационного обеспечения выработки решений по управлению качеством данных систем. В качестве рекомендации, представлены унифицированные модели процессов формирования организационно-распорядительных, информационно-справочных и конструкторских документов в виде алгоритмов их реализации.

Ключевые слова: автоматизированная система военного назначения, средства автоматизации, жизненный цикл системы, управляющие решения, качество системы, виды документов.

Вестник ТвГУ. Серия: Прикладная математика. 2019. № 3. С. 53-63. https://doi.org/10.26456/vtpmk539

\section{Введение}

Анализ нормативных документов, регламентирующих процессы жизненного цикла (ЖЦ) автоматизированной системы военного назначения (ACBH) позволяет классифицировать процессы информационно-аналитической деятельности (ИАД) субъектов ЖЦ АСВН по видам формируемых документов, обеспечивающих выработку решений по управлению качеством АСВН (PУK) ${ }^{1}$ с целью последующей автоматизации процессов документационного обеспечения данных управленческих решений на всех стадиях и этапах ЖЦ АСВН $[1,2]$. Это особенно актуально в настоящее время, когда несмотря на достаточно высокую оснащённость

\footnotetext{
1 Решение по управлению качеством АCBН (PУK) - задокументированная информация, обосновывающая целесообразность перехода к очередной стадии и (или) этапу ЖК АСВН, а также отражающая состояние и порядок проведения организационно-технических мероприятий, влияющих на изменение характеристик качества АCBН и её компонентов.
} 
субъектов ЖЦ АСВН современными информационно-коммуникационными технологиями, их взаимодействие при выработке управленческих решений осуществляется в ручном режиме посредством бумажного документооборота.

\section{1. Сущность метода}

Предлагаемый метод определяет порядок построения и оптимизацию моделей процессов ИАД субъектов ЖЦ АСВН по видам формируемых документов для их последующей автоматизации. Сущность метода заключается в последовательном выполнении пронумерованных этапов, представленных на Рис. 1.

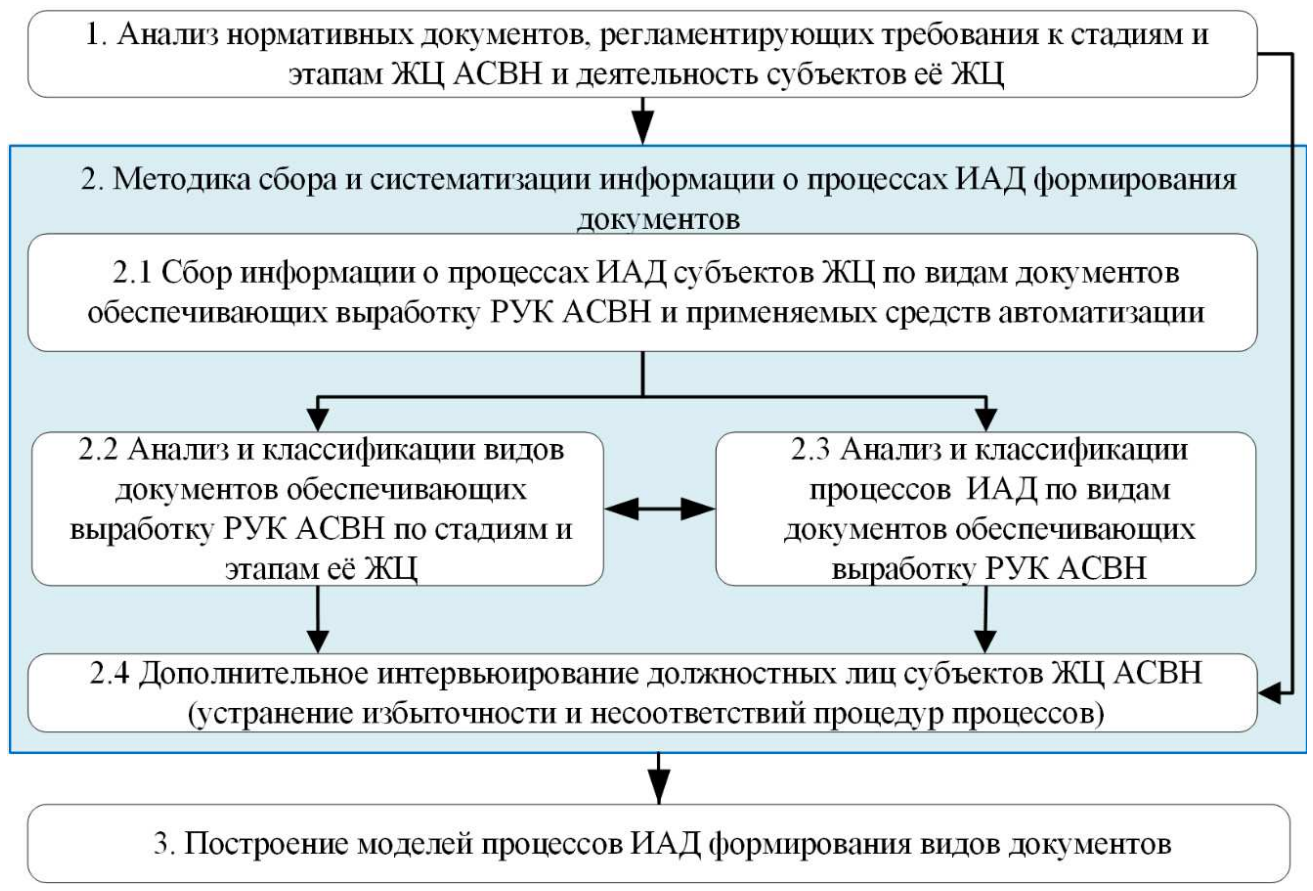

Рис. 1: Схема метода построения моделей процессов ИАД субгектов ЖЦАСВН

На первом этапе данного метода осуществляется анализ нормативных документов, регламентирующих требования к АCBН и деятельность субъектов её ЖЦ применительно к стадиям и этапам ЖЦ $\mathrm{ACBH,} \mathrm{в} \mathrm{рамках} \mathrm{которого} \mathrm{рассматрива-}$ ются:

- нормативные документы, регламентирующие процедуры работы с документами, номенклатуру дел и функциональные обязанности должностных лиц, требования и нормы по защите информации, правам доступа к ней, порядок контроля достоверности информации, её целостности, хранением информации;

- стандарты предприятий, регламентирующие работу с организационными и административными документами, ведением архивов, ответственность должностных лиц и структурных подразделений; 
- формы документов (регистрационные и контрольные карточки, журналы регистрации, приказы, распоряжения, бланки, письма и другие);

- отчётные формы (сводки, отчёты об исполнении, объем документооборота и другие);

- справочные документы, содержащие унифицированные массивы данных, их атрибуты и реквизиты, источники информации, способы её поступления, порядок использования;

- другие материалы (топология сети, концепция развития ИТ, результаты других обследований и заключений), предоставленные специалистами объектов обследования.

В основу второго этапа данного метода положена «Методика сбора и систематизации информации о процессах ИАД формирования документов», первый этап реализации которой осуществляется путём разработки и заполнение анкеты для сбора информации о процессах ИАД субъектов ЖЦ АСВН по видам документов, обеспечивающих выработку РУК. Анкета разрабатывается (корректируется) группой экспертов-аналитиков на основе информации полученной в результате анализа нормативных документов регламентирующих деятельность субъектов её ЖЦ. Апробированная при внедрении электронного документооборота форма анкеты $[3,4]$, обеспечивающая сбор информации о процессах ИАД должностных лиц $\mathrm{AO} \ll$ НИИИТ» ${ }^{2}$, представлена в таблице.

В качестве основных способов сбора информации предлагается использовать параллельные методы анкетирования, путём рассылки электронных версий анкет. По результатам обработки анкет формируются справочники документов, процессов (подпроцессов) и должностных лиц субъектов ЖЦ АСВН, участвующих в выработке решений, влияющих на качество АСВН применительно к стадиям и этапам её ЖЦ. Кроме того, осуществляется сбор и систематизация шаблонов и форм документов выводимых на печать. В целом, справочники представляют собой структурированное описание предметной области и применяются в дальнейшем на этапах проектирования и разработки средств автоматизации процессов ИАД, как основной источник информации, поэтому свод данных целесообразно производить в электронной таблице средствами MS Excel, это позволит оперативно вносить соответствующие корректировки, осуществлять сортировку и фильтрацию данных.

В зависимости от количества документов, их анализ и классификация может осуществляется экспертным методом, путём последовательного перебора и систематизации документов по их видам и этапам ЖЦ АСВН в единой электронной таблице, но так как количество документов и разнородность процессов их формирования могут быть довольно значительными, то классификацию процессов по видам документов целесообразно осуществлять методом кластерного анализа (кластеризация): агломеративный - классификация реализуется произвольным количеством кластеров; дивизионной - классификация может происходить на заданное исследователем количество кластеров. В результате кластеризации, оказавшиеся в одной

2 АО «Научно исследовательский институт информационных технологий» на протяжении нескольких десятилетий успешно выполняет функции головного исполнителя работ на всех стадиях ЖЦ разрабатываемых и изготавливаемых им АСBН. 
Таблица 1: Пример анкеты для сбора информации о прочессах ИАД субгектов ЖЦ АСВН по видам документов, обеспечивающих выработку РУК

\begin{tabular}{|c|c|c|c|c|c|}
\hline Вид документа & \begin{tabular}{l|} 
Откуда \\
посту- \\
пает \\
(разра- \\
батывает)
\end{tabular} & $\begin{array}{l}\text { Куда } \\
\text { передаётся } \\
\text { (разраба- } \\
\text { тывает) }\end{array}$ & $\begin{array}{l}\text { Кто согла- } \\
\text { совывает } \\
\text { (норматив- } \\
\text { ный срок, } \\
\text { часы) }\end{array}$ & $\begin{array}{l}\text { Кто } \\
\text { Утверждает } \\
\text { (норматив- } \\
\text { ный срок, } \\
\text { часы) }\end{array}$ & $\begin{array}{l}\text { Приме- } \\
\text { няемые } \\
\text { средства }\end{array}$ \\
\hline \multicolumn{6}{|c|}{ ЭТАПЫ ЖИЗНЕННОГО ЦИКЛА АСВН } \\
\hline \multicolumn{6}{|c|}{ Этап (ОКР) - Разработка эскизного проекта } \\
\hline $\begin{array}{l}\text { План совмест- } \\
\text { ных работ на } \\
\text { выполнение } \\
\text { ОКР (СЧ ОКР })\end{array}$ & Заказчик & $\begin{array}{l}\text { Разработ- } \\
\text { чик }\end{array}$ & $\begin{array}{l}\text { Заказчик } \\
\text { (1) }\end{array}$ & $\begin{array}{l}\text { Разработ- } \\
\text { чик } \\
(0,5)\end{array}$ & $\begin{array}{l}M S \\
\text { Project }\end{array}$ \\
\hline $\begin{array}{l}\text { План мероприя- } \\
\text { тий по ката- } \\
\text { логизачии пред- } \\
\text { метов снабже- } \\
\text { ния... }\end{array}$ & 1 & $\begin{array}{l}\text { Разработ- } \\
\text { чик }\end{array}$ & $\begin{array}{l}\text { Заказчик } \\
\text { (1) }\end{array}$ & $\begin{array}{l}\text { Разработ- } \\
\text { чик } \\
(0,5)\end{array}$ & $\begin{array}{l}M S \\
\text { Excel }\end{array}$ \\
\hline \multirow{2}{*}{\multicolumn{6}{|c|}{$\begin{array}{l}\ldots \\
\text { Этап (ОКР) - Утверждение конструкторской доку- } \\
\text { ментации для организации промышленного (серийно- } \\
\text { го) производства изделий }\end{array}$}} \\
\hline & & & & & \\
\hline $\begin{array}{lr}\text { Aкт о завер- } \\
\text { шении коррек- } \\
\text { тировки } \text { КД } \\
\text { и доработки } \\
\text { опътного об- } \\
\text { разиа изделия } \\
\text {.. }\end{array}$ & $\begin{array}{l}\text { Разработ- } \\
\text { чик }\end{array}$ & - & - & $\begin{array}{l}\text { Заказчик } \\
\text { Разработ- } \\
\text { чик } \\
(0,5)\end{array}$ & $\begin{array}{l}M S \\
\text { Word }\end{array}$ \\
\hline ... & & & & & \\
\hline
\end{tabular}

группе виды документов, должны быть сходными (однородными) между собой по порядку реализации основных видов процедур процессов ИАДД ${ }^{3}$ формирования данных видов документов, таких как: рассмотрения, согласования, утверждения и прочих процедур. Требования к видам документов и состав участвующих в их формировании субъектов ЖЦ АСВН регламентируются нормативно-правовыми актами, системой государственных стандартов и общих технических требований в части разработки, производства и эксплуатации АСВН.

На заключительном этапе данной методики осуществляется дополнительное интервьюирование должностных лиц субъектов ЖЦ АСВН с целью устранение избыточности и несоответствий всех процедур процессов ИАД формирования определённых видов документов путём реализации алгоритма выполнения

\footnotetext{
3 Под реализацией процедуры процесса ИАД понимается процесс, в рамках которого были выполнены все операции и требования к временным характеристикам реализации процесса.
} 
операций конкретных процедур должностными лицами, участвующими в выработке РУК на соответствующих стадиях ЖЦ АСВН. Для этого пользуются ранее рассмотренными нормативными документами, регламентирующими требования к АСВН и деятельность субъектов её ЖЦ, это позволяет снять терминологическую и процедурную неопределённость.

Выполнение данного этапа целесообразно осуществлять путём последовательного сведения имеющихся данных, средствами MS Excel в единую таблицу и привязки каждого процесса ИАД к соответствующему виду документа. Использование системы фильтрации MS Excel обеспечит сортировку (группировку) и подсчёт количества видов документов по советующим процессам, анализ которых позволит обеспечить унификацию однотипных алгоритмов реализации процессов ИАД по обработке соответствующих видов документов, объединённых в группы (классы). При этом поля таблицы не требующие изменения должны быть защищены (заблокированы) на предмет внесения в них изменений (корректировок), что в последствии позволит облегчить сведение информации в общую таблицу и её анализ. В случае выявления неразрешимых противоречий, например, при желании интервьюируемого должностного лица изменить установленный нормативным документом порядок формирования документа, то возможно повторение проведение отдельных этапов, как правило, в форме личных интервью с привлечением профильных специалистов и экспертов в локальных предметных областях (документооборот, менеджмент качества, защита информации и другие).

На третьем этапе рассматриваемого метода осуществляется построение моделей реализации процесса ИАД формирования соответствующих видов документов, классифицированных на предыдущем этапе данного метода, в рамках которого уточняется последовательность движения документа и определяется порядок реализации процедур, состоящих из операций формирования документа соответствующего вида.

Для построения моделей процессов ИАД формирования соответствующих видов документов, как правило используют способы текстового, табличного и графического описания процессов деятельности. Графическое описание процессов деятельности, считается наиболее приемлемым способом, т.к. облегчает восприятие и логический анализ процессов с одновременным построением модели процесса в соответствующих нотация ${ }^{4}$, а также обеспечивает визуализацию алгоритма реализации процесса ИАД формирования определённого вида документа. Графическое описание процессов может быть представлено в схематической форме, например, с использованием средств MS Visio. Простота и наглядность этих схем позволяет работать с ними даже специалистам, не имеющим навыков системного анализа. Кроме того, применение графического описания процессов ИАД формирования соответствующих видов документов позволяет обеспечить их детальный анализ на предмет оптимальной организации выполняемых процедур и операций, выявления узких мест.

Построение моделей процессов данного уровня рекомендуется осуществлять в нотациях EPC или BPMN с применением специализированных инструменталь-

\footnotetext{
${ }^{4}$ Нотация - способ моделирования предметной области в рамках той или иной методологии. Нотация включает в себя множество условных обозначений в виде символов, используемых для представления понятий и их взаимоотношений, составляющее алфавит нотации, а также правила их применения.
} 
ных средств, работа с которыми требует определённых знаний и навыков взаимодействия со средствами графического интерфейса пользователя специальных программных продуктов [5].

\section{2. Унифицированные модели процессов ИАД формирования докумен-} тов

С целью последующей автоматизацию процессов документационного обеспечения ИАД субъектов ЖЦ АСВН, предлагается рассмотреть апробированные модели процессов ИАД формирования организационно-распорядительных, информационно-справочных и конструкторских документов в виде алгоритмов их реализации средствами MS Visio в нотациях «Процесс» или «Процедура»[3].

Организационно-распорядительные документы (ОРД) являются регулятором существующей системы управления качеством АСВН на всех этапах её ЖЦ. Данные документы содержат решения, идущие «сверху-вниз» в раках установленной системы взаимодействия субъектов ЖЦ АСВН, являясь юридическими фактами, вызывающими возникновение конкретных административно-правовых отношений. Процесс ИАД формирования ОРД состоит из процедур разработки, согласования и утверждения документа, состав и последовательность реализации которых представлена на Рис. 2 в виде унифицированной модели процесса ИАД формирования ОРД.

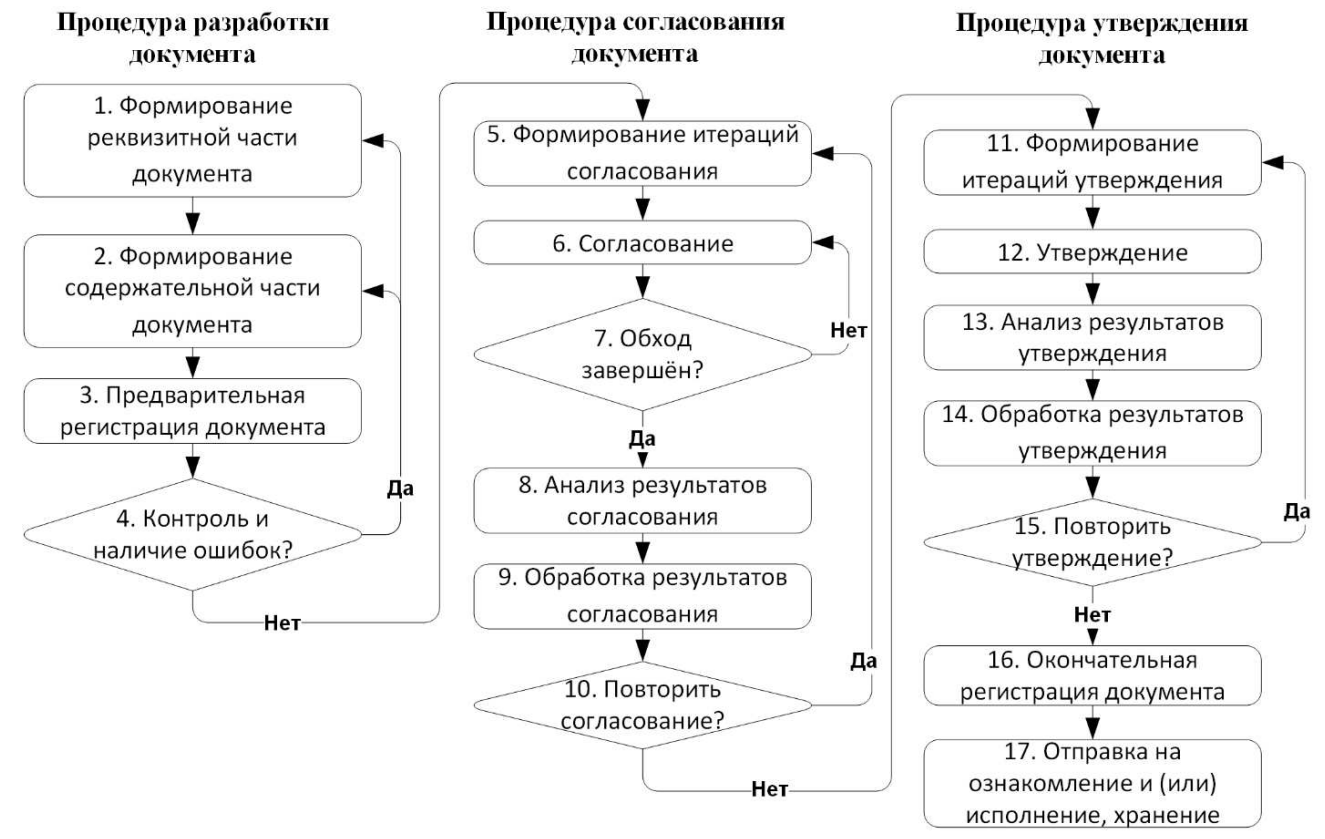

Рис. 2: Унифицированная модель процесса ИАД формирования ОРД

Реализацию данной модели целесообразно применять при автоматизации процессов ИАД формирования следующих ОРД: технические задания на создание 
(развитие) $\mathrm{ACBH} \mathrm{и} \mathrm{её} \mathrm{компонентов;} \mathrm{контракты} \mathrm{(договора)} \mathrm{на} \mathrm{выполнение} \mathrm{работ;}$ приказы, указания, распоряжения о проведении работ; решения (совместные решения); планы (планы-графики) проведения работ; протоколы согласования, разногласий; акты о завершении работ (в рамках этапов, стадий); акты приёма-сдачи, передачи; руководящие указания по правилам разработки программ и оформлению документов, инструкции; обеспечивающие программы, программы и методики испытаний.

Информационно-справочные документы (ИСД) являются побудителем к принятию определённых решений (инициируют решения) и не содержат поручений (не обязывают выполнять поручения). Особенностью данных документов является то, что они идут «снизу-вверх» по системе взаимодействия субъектов ЖЦ ACBН: от эксплуатанта к изготовителю, от изготовителя к разработчику т.д. Процесс ИАД формирования ИСД состоит из процедур разработки, согласования и рассмотрения документа, состав и последовательность реализации которых представлена на Рис. 3 в виде унифицированной модели процесса ИАД формирования ИСД.

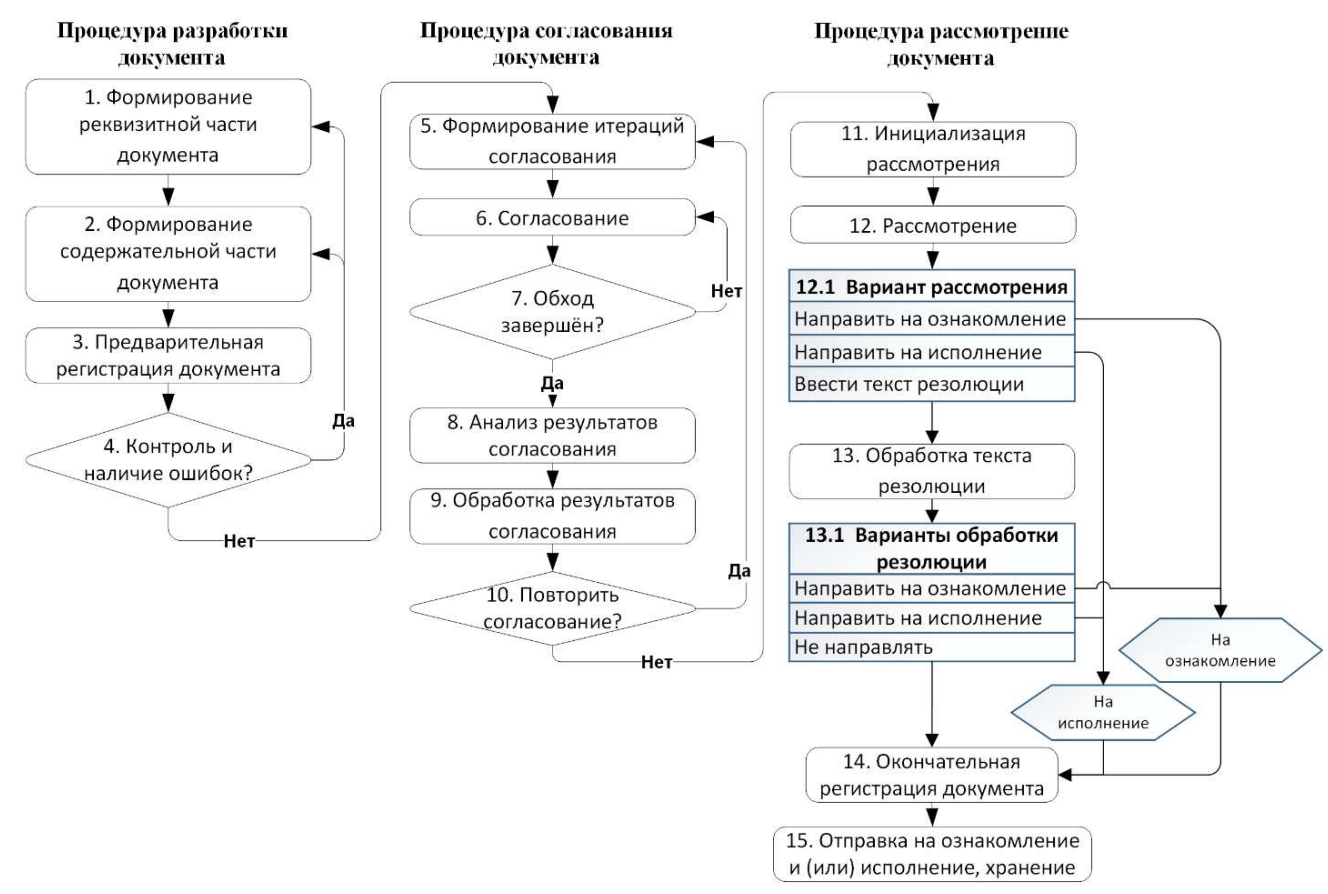

Рис. 3: Унифичированная модель прочесса ИАД формирования ИСД

Реализацию данной модели целесообразно применять при автоматизации процессов ИАД формирования следующих ИСД: рекламационные акты, акты исследования, акты доработки, акты приёмки; письма, уведомления, извещения, донесения; акты и протоколы (испытаний, обследования, проверок, настроек и т.п.); справки, записки, технические предложения, отчёты; заключения, экспертные заключения, протоколы НТС; журналы регистрации и учёта (событий, документов 
и т.п.); исходные данные, анкеты, опросные формы (листы).

Конструкторские документы (КД) определяют характеристики изделия, необходимые для его изготовления, контроля, приёмки, сборки, эксплуатации, ремонта и утилизации. Особенность данных документов в том, что они являются совокупностью проектных решений по структуре и характеристикам $\mathrm{ACBH}$ и всем видам её обеспечения, автоматизируемым процессам (функциям) и задачам, решаемых на каждом уровне иерархии системы. Процесс ИАД формирования КД состоит из процедур разработки, согласования, нормоконтроля и утверждения документа, состав и последовательность реализации которых представлена на Рис. 4 в виде унифицированной модели процесса ИАД формирования КД.

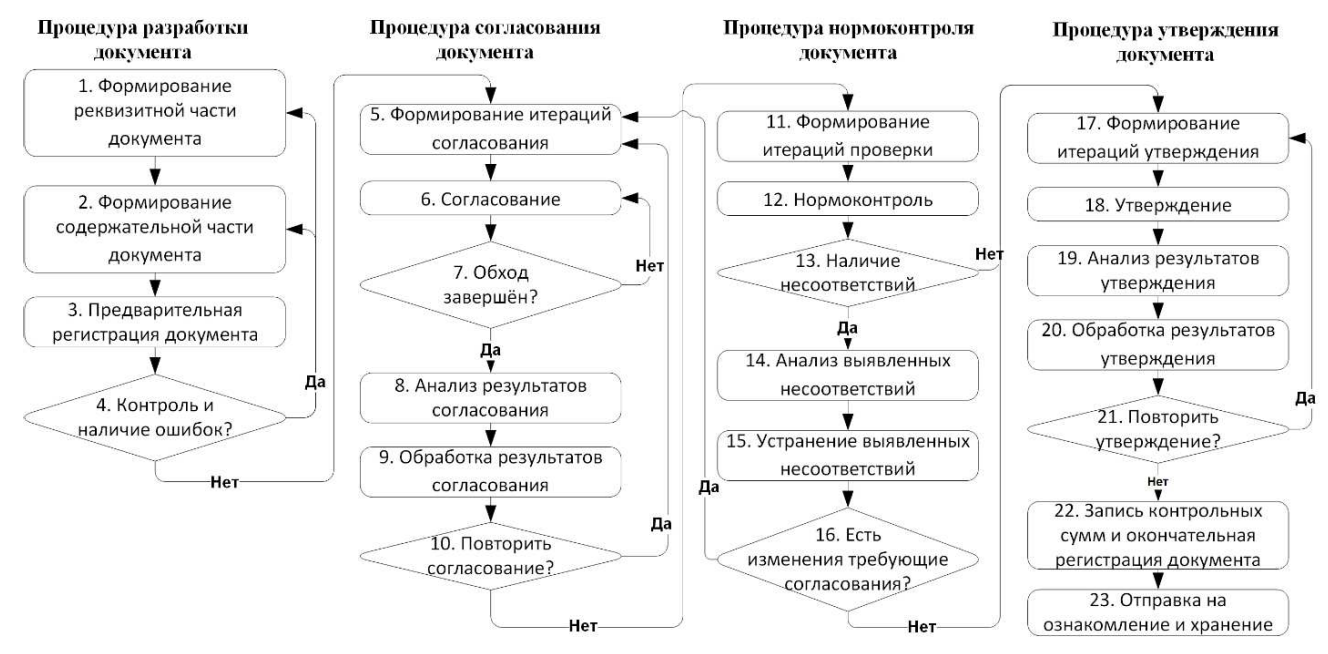

Рис. 4: Унифичированная модель прочесса ИАД формирования КД

Реализацию данной модели целесообразно применять при автоматизации процессов ИАД формирования следующих ИСД: ведомости программных документов, программ, вычислительных средств, технических средств; эскизные проекты; технические проекты; протоколы обмена данными; программные документы; рабочие проекты; технические условия; извещения об изменении (предварительные, предложения об изменении); эксплуатационные документы (на систему, комплексы и средства автоматизации).

\section{Заключение}

Таким образом, применение данного метода позволяет провести построение моделей процессов ИАД субъектов ЖЦ АСВН в части формирования документов обеспечивающих выработку РУК, при этом каждая из моделей характеризуется определённым составом процедур, включающих в себя соответствующее количество операций, анализ которых помогает вскрыть слабые (узкие) места в существующих процессах ИАД субъектов ЖЦ АСВН, и определить достаточный состав необходимых видов документов и процессов их формирования применительно ко всем стадиям и этапам ЖЦ АСВН. 


\section{Список литературы}

[1] Лясковский В.Л., Говоритель В.В. К вопросу применения международных стандартов при оценке качества автоматизированных систем военного назначения // Сборник научно-методических трудов II Всероссийской научнопрактической конференции «Актуальные вопросы развития вооружения, военной и специальной техники войск противовоздушной и противоракетной обороны, космических войск Воздушно-космических сил». 2017. С. 229-232.

[2] Лясковский В.Л. Системотехнические основы автоматизации процессов обработки информации и управления в иерархических системах военного назначения. Тверь: ВА ВKO, 2014. 244 с.

[3] Говоритель В.В. Опыт автоматизации управления проектами в ОАО «НИИИТ» с использованием системы электронного документооборота // Сборник докладов III конференции «Информационные технологии на службе оборонно-промышленного комплекса России». Тверь: ВА ВKO, 2014.

[4] Бреслер И.Б. Работа с документами - в едином информационном пространстве // Умное производство. 2017. № 3 (39). С. 60-63.

[5] Репин В.В. Бизнес-процессы компании: построение, анализ, регламентация. М.: Стандарты и качество, 2007. 240 с.

\section{Образец цитирования}

Элькин Г.И., Говоритель В.В. Метод построения моделей процессов информационно-аналитической деятельности субъектов жизненного цикла автоматизированных систем военного назначения // Вестник ТвГУ. Серия: Прикладная математика. 2019. № 3. C. 53-63. https://doi.org/10.26456/vtpmk539

\section{Сведения об авторах}

\section{1. Элькин Григорий Иосифович}

генеральный конструктор по АСУ и связи ВС РФ, заместитель генерального директора $\mathrm{AO}$ «Объединённая приборостроительная корпорация».

Россия, 121357, г. Москва, ул. Верейскал, д. 29, стр. 141.

\section{2. Говоритель Владимир Владимирович}

докторант военной академии воздушно-космической обороны имени Маршала Советского Союза Г.К. Жукова.

Россия, 170100, г. Тверь, ул. Жигарева, д. 50, ВА ВКО им. Г.К. ЖКукова. 


\title{
THE METHOD OF CONSTRUCTING MODELS OF PROCESSES OF INFORMATION AND ANALYTICAL ACTIVITIES OF THE SUBJECTS OF THE LIFE CYCLE OF AUTOMATED MILITARY SYSTEMS
}

\author{
Elkin Grigoriy Iosifovich
}

General Designer for Automated Control Systems and Communications of the Armed Forces of the Russian Federation, Deputy General Director, United Instrument Manufacturing Corporation JSC

Russia, 121357, Moscow, 29 Vereyskaya str., building 141.

Govoritel Vladimir Vladimirovich

doctoral student at Military Aerospace Defense Academy named after Marshal of the Soviet Union G.K. Zhukov

Russia, 170100, Tver, 50 Zhigareva str., MADA.

Received 27.08.2019, revised 20.09.2019.

The method considered in the article allows one to reduce the number of iterations for the informational survey of automation objects in terms of description, classification and construction of models of processes of informational and analytical activities of subjects of the life cycle of automated military systems for the purpose of subsequent automation of documentation processes for developing decisions on the quality management of these systems. As a recommendation, unified models of the processes of formation of organizational and administrative, information and reference and design documents in the form of algorithms for their implementation are presented.

Keywords: military automated system, automation tools, system life cycle, control decisions, system quality, types of documents.

\section{Citation}

Elkin G.I., Govoritel V.V., "The method of constructing models of processes of information and analytical activities of the subjects of the life cycle of automated military systems", Vestnik TvGU. Seriya: Prikladnaya Matematika [Herald of Tver State University. Series: Applied Mathematics], 2019, № 3, 53-63 (in Russian). https://doi.org/10.26456/vtpmk539

\section{References}

[1] Lyaskovskij V.L., Govoritel V.V., "On the issue of applying international standards in assessing the quality of automated military systems", Sbornik nauchno-metodicheskikh trudov II Vserossijskoj nauchno-prakticheskoj konferentsii "Aktualnye voprosy razvitiya vooruzheniya, voennoj i spetsialnoj tekhniki 
vojsk protivovozdushnoj i protivoraketnoj oborony, kosmicheskikh vojsk Vozdushnokosmicheskikh sil" [Collection of scientific and methodological works of the II AllRussian scientific and practical conference "Actual issues of the development of weapons, military and special equipment of the air defense and missile defense forces, space forces of the Aerospace Forces"], 2017, 229-232 (in Russian).

[2] Lyaskovskiy V.L., Sistemotekhnicheskie osnovy avtomatizatsii protsessov obrabotki informatsii $i$ upravleniya $v$ ierarkhicheskikh sistemakh voennogo naznacheniya [System-technical foundations of automation of information processing and control processes in hierarchical military systems], VA VKO Publ., Tver, 2014 (in Russian), 244 pp.

[3] Govoritel V.V., "Experience in project management automation at NIIIT using an electronic document management system", Sbornik dokladov III konferentsii "Informatsionnye tekhnologii na sluzhbe oboronno-promyshlennogo kompleksa Rossii" [Collection of reports of the III conference "Information technology in the service of the military-industrial complex of Russia"], VA VKO Publ., Tver, 2014 (in Russian), 244 pp.

[4] Bresler I.B., "Work with documents - in a single information space", Umnoe proizvodstvo [Smart manufacturing], 2017, № 3 (39), 60-63 (in Russian).

[5] Repin V.V., Biznes-protsessy kompanii: postroenie, analiz, reglamentatsiya [Business processes of the company: construction, analysis, regulation], Standards and Quality Publ., M., 2007 (in Russian), 240 pp. 